This item was submitted to Loughborough's Research Repository by the author.

Items in Figshare are protected by copyright, with all rights reserved, unless otherwise indicated.

\title{
Bipolar modulation of the output of a 10-GW pulsed power generator
}

PLEASE CITE THE PUBLISHED VERSION

http://dx.doi.org/10.1109/TPS.2016.2569461

PUBLISHER

(c) IEEE

VERSION

AM (Accepted Manuscript)

LICENCE

CC BY-NC-ND 4.0

REPOSITORY RECORD

Wang, Meng, Bucur M. Novac, Laurent Pecastaing, and Ivor R. Smith. 2019. "Bipolar Modulation of the Output of a 10-GW Pulsed Power Generator". figshare. https://hdl.handle.net/2134/21928. 


\title{
Bipolar Modulation of the Output of a 10-GW Pulsed Power Generator
}

\author{
Meng Wang, Student Member, IEEE, Bucur M. Novac, Senior Member, IEEE, Laurent Pécastaing, \\ and Ivor R. Smith, Senior Member, IEEE
}

\begin{abstract}
A bipolar Blumlein former has been designed and successfully implemented as an extension to an existing 10-GW-Tesla-driven Blumlein pulsed power generator. The new system is capable of generating a voltage impulse with a peak-topeak value reaching $650 \mathrm{kV}$ and having a high-frequency limit of the bandwidth well in excess of $1 \mathrm{GHz}$. Constructional details are provided, together with experimental results and analysis using the 3-D software modeling of the bipolar former that provides the results in good agreement with experimental data.
\end{abstract}

Index Terms-Pulse compression circuits, pulse modulation, pulsed power systems, transient propagation.

\section{INTRODUCTION}

A BROAD range of modern pulsed power applications, including plasma physics, lasers, particle accelerators, aeronautics, outer space science, food industry pulsed-electricfield (PEF) sterilization, bioelectric studies, medical cancer treatment, and the defense industry, require the generation of very fast high-voltage (HV) pulses. The development of a compact Tesla-transformer Blumlein pulse forming line (PFL) pulsed power generator capable of producing a monopolar $0.6 \mathrm{MV}$ voltage impulse with a rise time close to $2 \mathrm{~ns}$ and providing a peak electrical power of $10 \mathrm{GW}$ when connected to a $30 \Omega$ load was reported previously [1]. The first intended application is to use the generator for noninvasive medical cancer treatment, by attaching to its output an antenna to generate intense PEFs. However, it is straightforward to show that a monopolar voltage impulse is not well suited to feeding an antenna and that a bipolar signal will have the following advantages [2].

1) Better suited frequency spectrum, i.e., the low-frequency section of the monopolar pulse with frequencies less than $100 \mathrm{MHz}$, which cannot be radiated by a compact antenna, is greatly reduced in the bipolar pulse spectrum (see Fig. 1).

Manuscript received January 15, 2016; revised April 5, 2016; accepted May 4, 2016.

M. Wang, B. M. Novac, and I. R. Smith are with the Wolfson School of Mechanical, Electrical and Manufacturing Engineering, Loughborough University, Loughborough LE11 3TU, U.K. (e-mail: m.wang4@lboro.ac.uk; b.m.novac@lboro.ac.uk; i.r.smith@lboro.ac.uk).

L. Pécastaing is with the Laboratoire des Sciences de l'Ingénieur Appliquées à la Mécanique et au Génie Electrique, Equipe Génie Electrique, Université de Pau et des Pays de l'Adour, Pau 64053, France (e-mail: laurent.pecastaing@univ-pau.fr).

Color versions of one or more of the figures in this paper are available online at http://ieeexplore.iee.org.

Digital Object Identifier 10.1109/TPS.2016.2569461

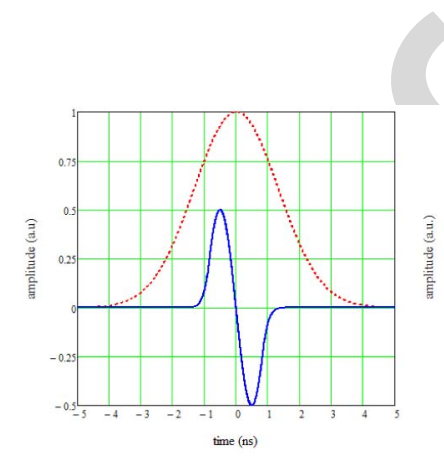

a)

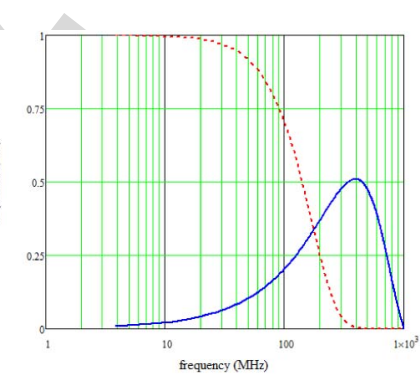

b)
Fig. 1. Comparison between a monopolar signal from a hypothetical generator (dotted red line) and its corresponding bipolar signal obtained from a bipolar former attached to the same generator (continuous blue line) in (a) time domain and (b) frequency domain.

2) Reduced risks of insulation breakdown by flashover include the following.

a) The low-frequency components of a monopolar pulse do not match the antenna characteristics and are reflected back to the generator. This unwanted phenomenon is absent in the case of a bipolar pulse.

b) The peak voltage of the bipolar pulses is only one half that of the peak voltage of the initial monopolar pulse, but, very importantly, the same peak-to-peak amplitude is maintained.

3) The bipolar signal lacks any dc spectral component, thus improving the operator safety, i.e., after a shot there is no risk of a residual charge on the arms of a not yet short-circuited antenna.

4) The technique used to generate a bipolar pulse, using a monopolar pulse as a driver, also usually performs time compression of the driving signal, thereby increasing the upper limit of its frequency spectrum (Fig. 1).

Pioneering work on bipolar formers to modulate the power output from powerful generators has been presented in [3]-[5]. The reported peak bipolar voltage output was $\pm 120 \mathrm{kV}$, with a duration of $1 \mathrm{~ns}$, for the use with a combined frequency transmitting antenna [3], $\pm 200 \mathrm{kV}$ for the use with an antenna array [4] and finally $\pm 350 \mathrm{kV}$, with a duration of $200 \mathrm{ps,}$ also for the use with an antenna array [5]. The application of these spectacular technological achievements is in the domain of high-resolution radars, electromagnetic compatibility, and other defense-related areas, which require for the systems to be capable of continuous operation at a high repetition rate 

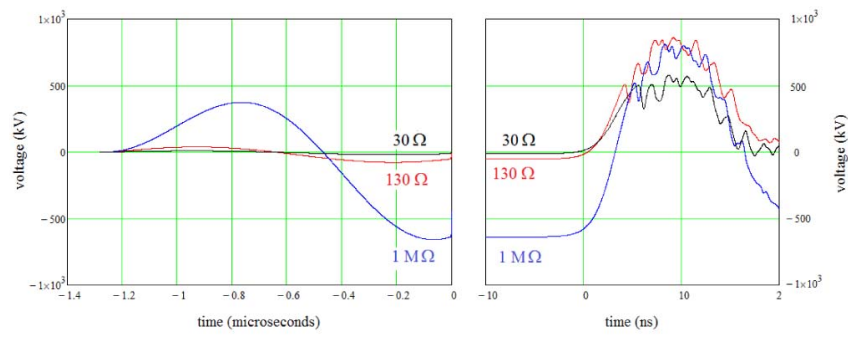

Fig. 2. Results from the PSPICE simulation of the Blumlein-PFL output voltage (left: during unit charging and right: during discharging) for three different values of a parallel-attached resistor: $30 \Omega, 130 \Omega$, and $1 \mathrm{M} \Omega$. Calculations performed with the bipolar former operated only with its seriesconnecting switch, i.e., without a crowbar. The time origin corresponds to closing of the switch that triggers the Blumlein-PFL discharge.

and for hours. This paper details the development of a bipolar former attached to the 10-GW-Tesla-Blumlein generator, with the aim of applying the output voltage impulses to an antenna for medical and biological applications, and for which neither a high repetition rate nor a long duration continuous operation is really required.

After presenting the preliminary work devoted to the changes required to the Blumlein PFL output to allow connection of a bipolar former, the design of the enhanced system is detailed, guided by Maxwell SV [6], PSPICE [7], and CST [8] software modeling. The results obtained during the development program are also presented, before concluding remarks that include a brief comment on the future step toward the development of a powerful PEF generator for medical applications.

\section{AdAPting the Blumlein PFL OUtPut FOR OPERATION WITH A BIPOLAR FORMER}

The existing 10-GW-Tesla-Blumlein PFL generator has so far been operated with a series-connected $30 \Omega$ resistive load [1]. As PSPICE simulation results show (Fig. 2), simply removing this resistor (equivalent to placing a $1 \mathrm{M} \Omega$ resistor in parallel, as shown in Fig. 2) and attaching the bipolar former to the Blumlein PFL output, or placing the resistor in parallel across the output electrodes (30 $\Omega$ in parallel; see Fig. 2) before attaching the bipolar former, are both unacceptable. In the first situation, the generated voltage has a very large and undesirable negative prepulse that may affect the proper functioning of the bipolar switches, and in the second, the positive amplitude signal is too low to be useful. After a few calculations and preliminary trials, an acceptable compromise solution was found in the form of a $130 \Omega$ resistor parallel-coupled with the Blumlein PFL output. Constructionally, this comprises ten identical aqueous $1.3 \mathrm{k} \Omega$ resistors ( $\mathrm{CuSO}_{4}$-doped demineralized water) placed in the radialsymmetrical configuration in Fig. 3. To minimize the possibility of electrical flashover, the liquid of each resistor (a liquid length of $100 \mathrm{~mm}$ and a diameter of $15 \mathrm{~mm}$ ) is contained within a Teflon cylinder, with both the inside and outside walls having a ribbed geometry. The resistors are operated under oil and calculations that predict that they will need to withstand a very high-output voltage impulse that may attain a value in

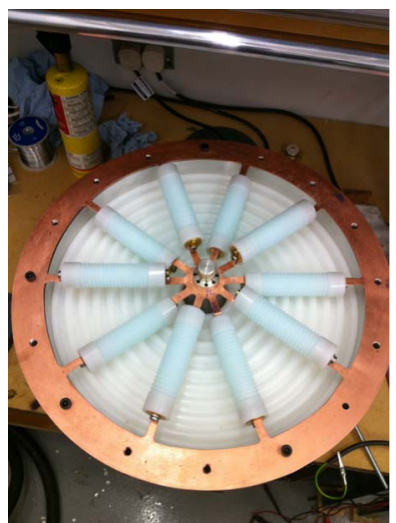

Fig. 3. $130 \Omega$ resistor. When connected to the output of the Blumlein PFL generator, the remaining empty space is filled with transformer oil.

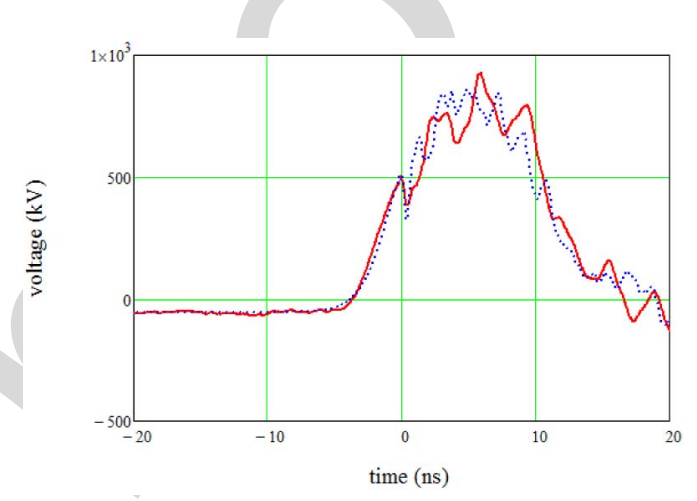

Fig. 4. Blumlein-PFL output voltage with a parallel-connected $130 \Omega$ resistor and a bipolar former operated without a crowbar. Continuous red line: experimental data. Blue dotted line: corresponding PSPICE simulation. The time origin is from the action of the $500-\mathrm{kV}$ bipolar former first closing switch, connecting the unit to the Blumlein PFL.

excess of 0.6 MV, larger than the designed peak voltage inside the Blumlein PFL. A series of experiments was, therefore, performed to test the resistors and the Blumlein PFL under HV loading, by operating the bipolar former (described later) without its second crowbar switch. The results obtained clearly demonstrate that the resistors are capable, together with the central electrode of the Blumlein PFL, of maintaining their electrical integrity up to and even above 0.9 MV (see Fig. 4), a performance well in excess of the design expectations.

\section{Design, Manufacture, And Modeling THE BIPOLAR FORMER}

\section{A. Design and Manufacture}

Fig. 5 shows that the bipolar former has a design similar to that of a conventional Blumlein PFL with two transmission lines each of $25 \Omega$ and a coaxial output of $50 \Omega$, but with two closing switches installed at its input: one in series for connection to the power source (usually not installed in a conventional Blumlein PFL) and the other in parallel (part of a conventional Blumlein PFL) for discharge of the unit. The action of the bipolar former is dictated by the dynamics of the two switches and was presented elsewhere [3], with a much simpler albeit incomplete description being provided in the following. 


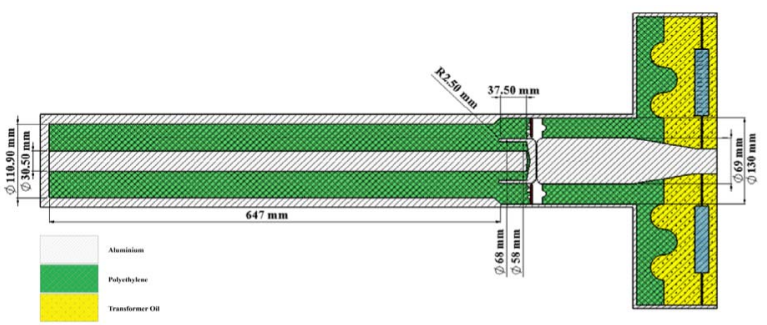

a)

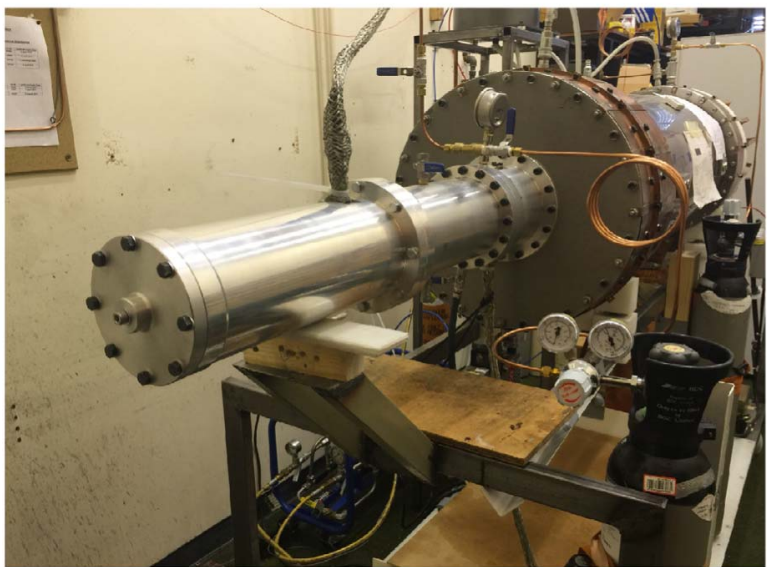

b)

Fig. 5. Bipolar former. (a) Schematic. (b) Assembled unit connected to the Tesla-Blumlein PFL output.

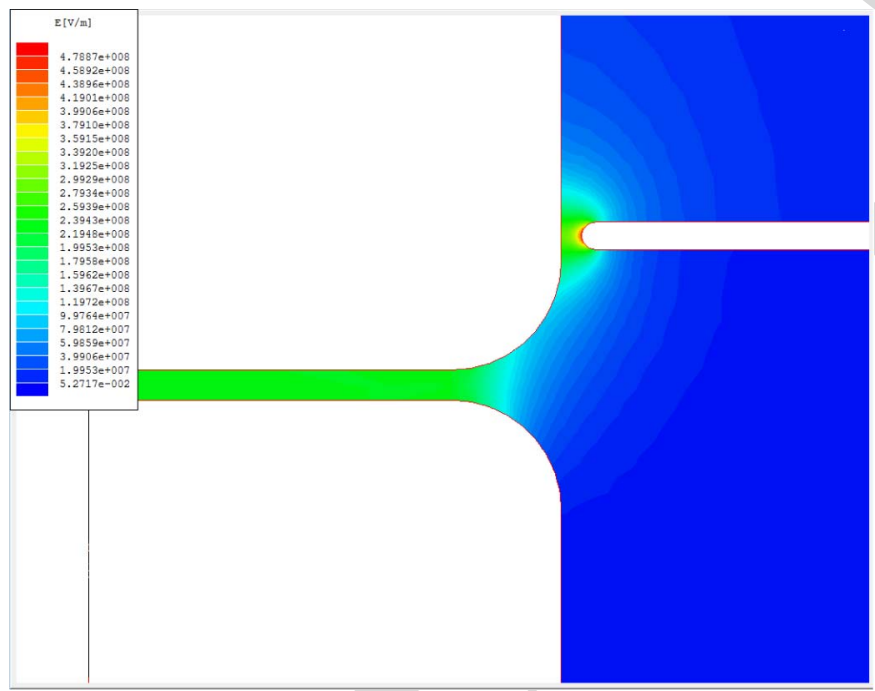

Fig. 6. Electric field distribution produced by the two switches mounted at the bipolar former input, with $0.5 \mathrm{MV}$ applied on the (lower) electrode corresponding to the HV output of the Blumlein PFL.

The positive driving monopolar impulse is allowed to rise to a very HV before the series-connected switch closes, attaching the bipolar unit to the driving generator. The electromagnetic energy transferred from the driving source is capable of very rapidly pulse charging the bipolar former, thereby performing pulse compression of the rise time of the driving monopolar pulse. During charging, a fraction of the fast positive voltage impulse is directly transferred to the load, with the bipolar

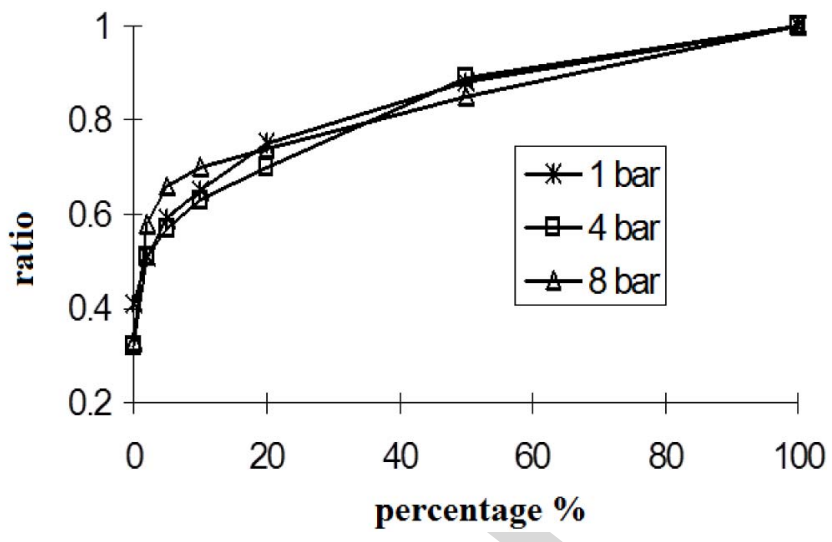

Fig. 7. Influence of percentage $\mathrm{SF}_{6}$ on the ratio of the electric field breakdown for $\mathrm{SF}_{6}-\mathrm{N}_{2}$ mixture to that of pure $\mathrm{SF}_{6}$ [9].

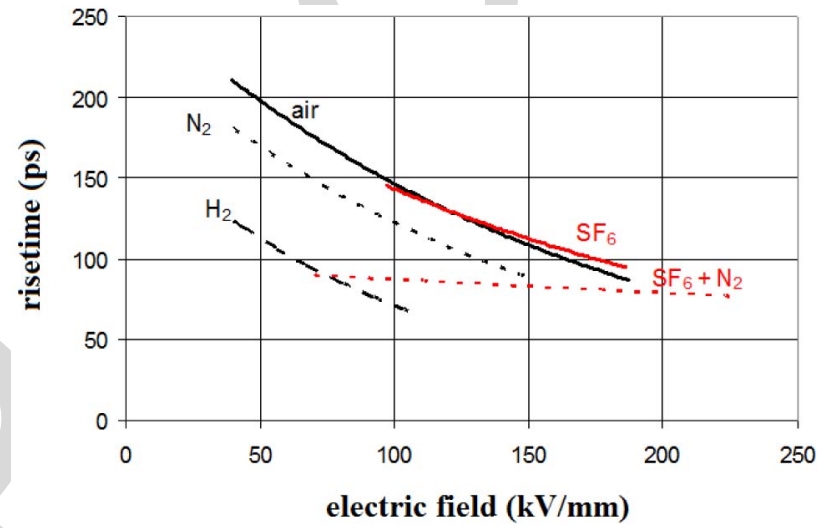

Fig. 8. Experimentally determined rise time of the voltage impulse as a function of the applied electric field for a closing switch using: $\mathrm{H}_{2}$, air, $\mathrm{N}_{2}$, pure $\mathrm{SF}_{6}$, and $\mathrm{SF}_{6}-\mathrm{N}_{2}(5 \%-95 \%)$ mixture [10].

former electrodes playing the role of a capacitive divider. The charging period ends with closure of the second crowbar switch triggering the discharge of the bipolar unit. As usual, discharge of the Blumlein PFL generates a voltage impulse with a polarity opposite to that of the charging polarity, i.e., the voltage generated by the bipolar former discharge in the load is negative. To ensure that the two opposite polarity voltage peaks delivered to the load are close, the gap and the geometry of both switches need to be precisely adjusted during a rather tedious process.

Manufacture of the bipolar former is straightforward, with the metallic electrodes made for convenience from aluminum and the insulators from ultrahigh molecular weight polyethylene of relative permittivity 2.4. During assembly, a thin layer of oil was introduced at each aluminum-polyethylene interface to eliminate any unwanted air. All experiments reported were performed with the $50-\Omega$ coaxial line output short circuited.

\section{B. Closing Switches}

As already mentioned, a pair of closing switches is installed at the bipolar former input. An electrostatic solver [6] was used to calculate both the electric field generated with $500 \mathrm{kV}$ applied to the driver HV electrode (Fig. 6) and also to obtain 


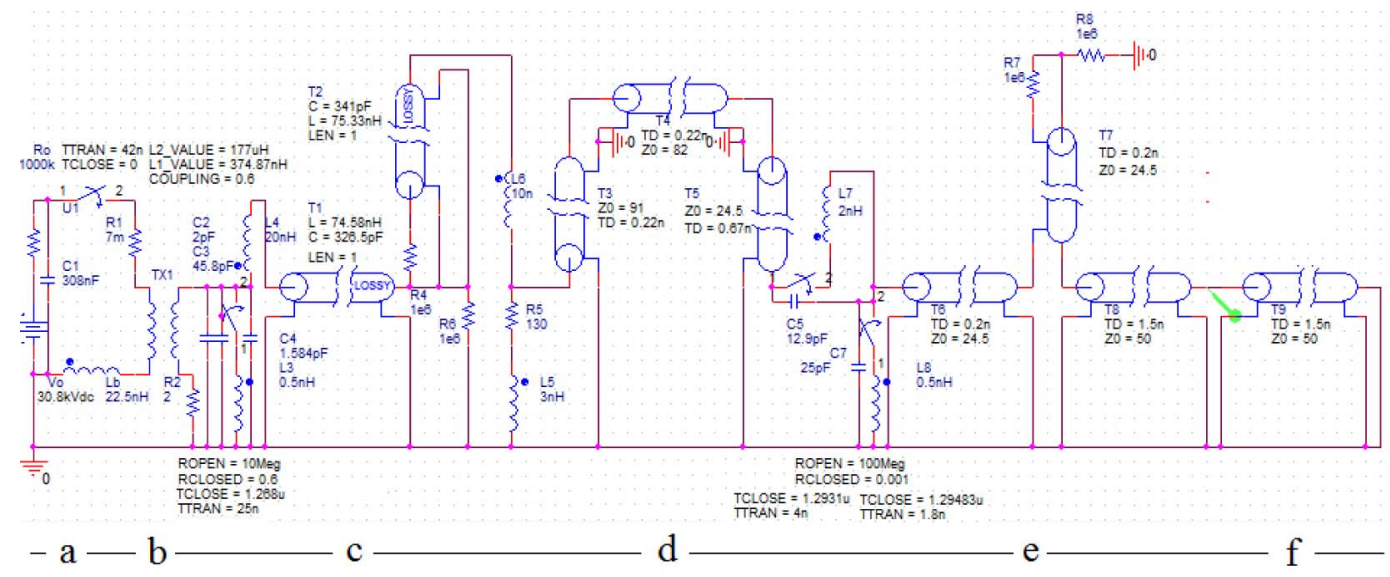

Fig. 9. PSPICE model of the entire pulsed power system. (a) HV charger. (b) Tesla transformer. (c) Blumlein PFL with a closing switch at its input and a $130 \Omega$ resistor parallel-connected at its output. (d) Three very short transmission lines. (e) Bipolar former with two switches mounted at its input. (f) Short-circuited $50-\Omega$ line output.

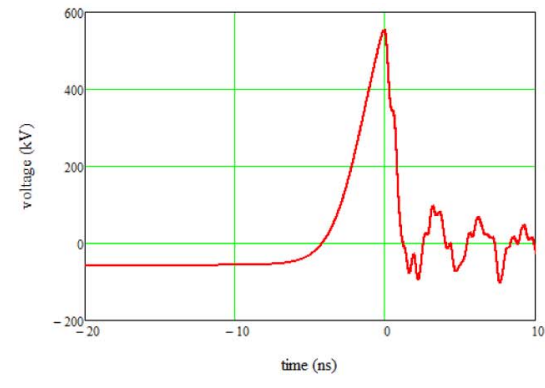

a)

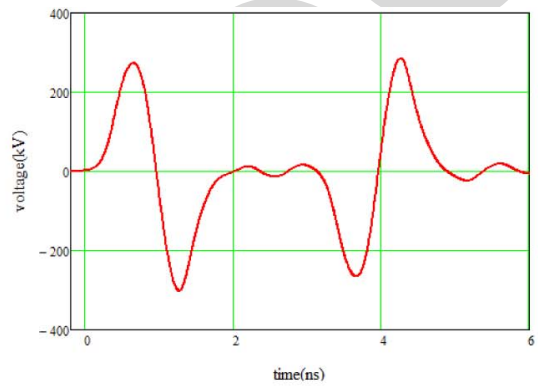

b)

Fig. 10. Main results from PSPICE modeling. (a) Blumlein output voltage impulse. (b) Bipolar voltage generated in the $50-\Omega$ output transmission line, followed by its reversed polarity mirror image produced by reflection at the short-circuited end. In both the cases, the time origin is from closure of the switch connecting the bipolar former to the Blumlein PFL.

the (prebreakdown) capacitances of the two switches, for the use in PSPICE modeling. Both the switches operate in pressurized gas at very $\mathrm{HV}$, and for both, it is desirable to provide the shortest rise time possible. In such cases, the best gas to be used is $\mathrm{H}_{2}$ (due to its low mass density) or, when this presents a risk, the alternative is $\mathrm{N}_{2}$. Both require very high pressures, but, unfortunately, in the present system, the maximum operable overpressure is only $20 \mathrm{bar}$, insufficient for the switches to operate at very HV. In order to withstand HV levels at lower pressure, $\mathrm{SF}_{6}$ can replace $\mathrm{H}_{2}$ or $\mathrm{N}_{2}$, but, due to its heavier molecular mass, the resulting rise time will become unacceptable long. Previous experience has demonstrated that $\mathrm{SF}_{6}-\mathrm{N}_{2}$ mixtures provide the simplest substitute for pure $\mathrm{SF}_{6}$, with even a small $\mathrm{SF}_{6}$ content resulting in a substantial increase in the breakdown electric field of pure $\mathrm{N}_{2}$. For example, it was experimentally demonstrated [9] that only $10 \%$ of $\mathrm{SF}_{6}$ is required to increase the critical reduced field of pure $\mathrm{N}_{2}$ to $\sim 70 \%$ of that of pure $\mathrm{SF}_{6}$ (Fig. 7). A somehow unexpected benefit, also demonstrated experimentally [10], is that the rise time of a switch operated with certain $\mathrm{SF}_{6}-\mathrm{N}_{2}$ mixtures can be lower than when pure $\mathrm{N}_{2}$ gas is used (Fig. 8). Based on these results, it was decided to operate the bipolar switches at 20 bar in a $10 \%-90 \% \mathrm{SF}_{6}-\mathrm{N}_{2}$ mixture.

\section{Diagnostics}

Three V-dot probes were installed inside the full generator assembly. The first of these, mounted in the outer wall of the Blumlein-PFL, was fully described and its sensitivity $k_{1}$ provided elsewhere [1]. The second and third probes, having sensitivities $k_{2} \approx 0.3 \mathrm{ps}$ and $k_{3} \approx 0.2 \mathrm{ps}$, are made from 18-GHz female-female N-type adaptors and placed, respectively, after the $130 \Omega$ resistor at the Blumlein-PFL transmission line output and in the wall of the bipolar former $50-\Omega$ output transmission line. A detailed study of V-dot probes made from off-the-shelf components is in preparation. These two probes are connected, using double shielded $18-\mathrm{GHz}$ coaxial cables and attenuators, to an $18-\mathrm{GHz}, 60-\mathrm{GS} / \mathrm{s}$ LeCroy real-time digital oscilloscope, with the output of the second probe taken to a 6-GHz-bandwidth input and that of the third probe to an 18-GHz input. The oscilloscope is housed in a Faraday box and powered by a UPS unit.

\section{Numerical Modeling}

Fig. 9 shows the PSPICE model for the entire system (Tesla-Blumlein PFL-bipolar former), and Fig. 10 shows the predicted voltage signal delivered by the bipolar former to the 


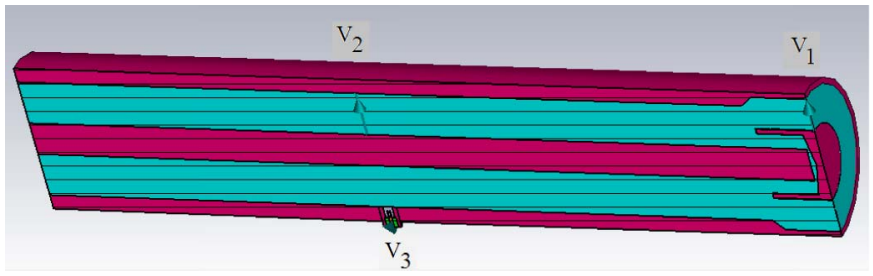

Fig. 11. CST model of the bipolar former. Three CST voltage monitors used in the numerical study are placed as follows: $V 1$ at the unit input (right hand side), $V 2$ across the $50-\Omega$ transmission line at a position corresponding to the (real) $\mathrm{V}$-dot probe, and $V 3$ at the probe output.
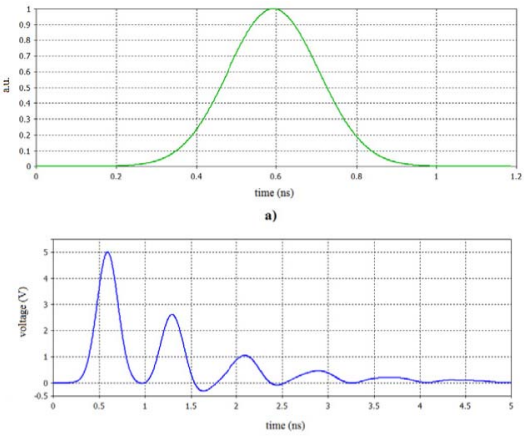

b)
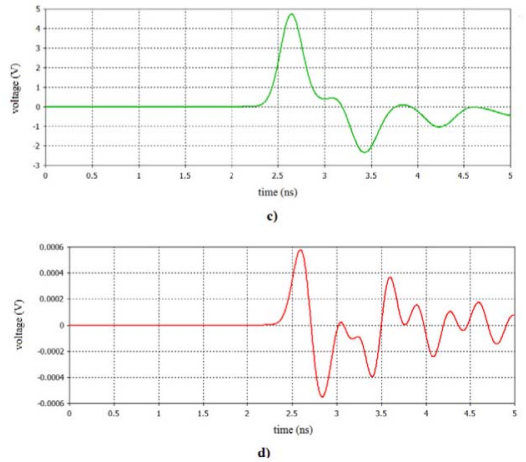

Fig. 12. Main results from CST study of the bipolar former and its V-dot probe. (a) 3-GHz excitation Gaussian signal applied at the input port. Output signals from the three voltage monitors of Fig. 11 are from (b) $V 1$, (c) $V 2$, and (d) $V 3$.

$50-\Omega$ output transmission line when the driver Blumlein-PFL generator operates close to its peak performance [1].

Fig. 11 shows the CST model for the bipolar former, including the V-dot probe inside the wall of the output transmission line. Fig. 12 shows the results with a Gaussian excitation impulse applied at the bipolar former CST input port [Fig. 12(a)] and using three voltage monitors in the software to indicate the voltage signal at various positions inside the unit. After the voltage signal at the input is modulated [Fig. 12(b)], it travels along the transmission line until reaching the position where the V-dot probe is mounted [Fig. 12(c)].

The proper functioning of this differential probe can be investigated by integrating its predicted output signal [Fig. 12(d)] and using the constant $k_{3}$ to compare the result with the voltage signal in Fig. 12(c). Such an analysis, together with a more advanced CST model currently under development and which includes the action of the two closing switches, will be presented elsewhere.

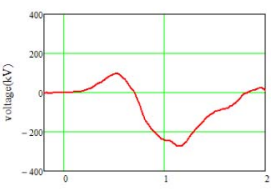

a)

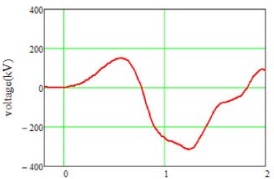

d)

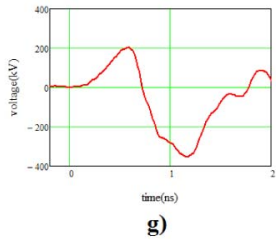

g)

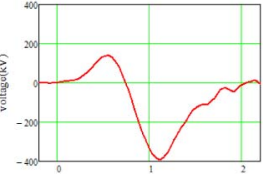

b)

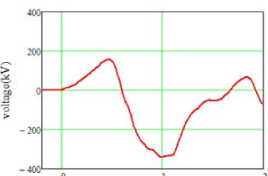

e)

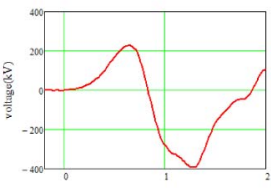

h)

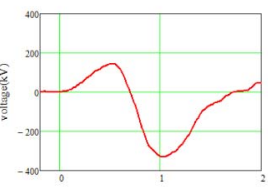

c)

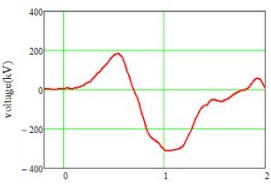

f)

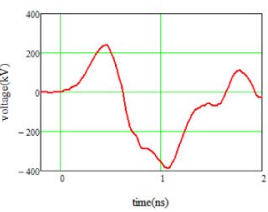

i)
Fig. 13. Load voltage impulses generated by the bipolar former during the process of adjusting the bipolar former switch gaps. Time origin from the connecting bipolar switch closure.
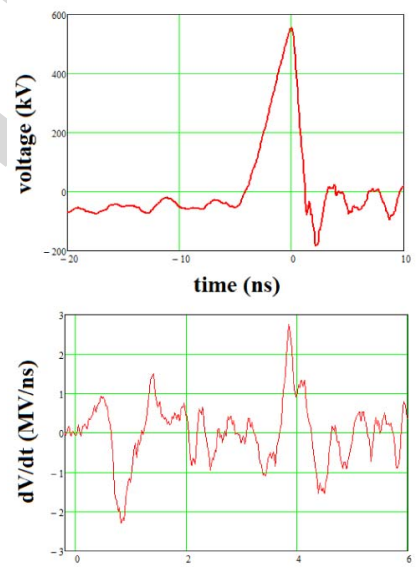

time (ns)

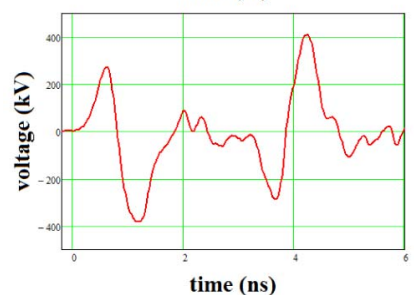

Fig. 14. Typical experimental results from the final pulsed power system. (a) Blumlein PFL output voltage impulse. (b) $d V / d t$ signal recorded by the bipolar output probe. (c) Integrated bipolar voltage developed in the $50-\Omega$ output transmission line, followed by its reversed polarity mirror image produced by reflection at the short-circuited end. In all the cases, the time origin is from the closure of the switch connecting the bipolar former to the Blumlein PFL.

\section{BIPOLAR FORMER EXPERIMENTAL RESUlTS}

Table I presents an overview of the main results obtained from an experimental study to establish the optimum combinations of the gaps of the two switches mounted at the bipolar former input. Correspondingly, Fig. 13 shows a number of 
TABLE I

Results From the Study of the Two Closing Switch Gaps of the Bipolar Former

\begin{tabular}{cccccc}
\hline \hline $\begin{array}{c}\text { Connecting } \\
\text { switch gap } \\
(\mathrm{mm})\end{array}$ & $\begin{array}{c}\text { Crowbar } \\
\text { switch gap } \\
(\mathrm{mm})\end{array}$ & $\begin{array}{c}\text { Positive voltage } \\
\text { peak } \\
(\mathrm{kV})\end{array}$ & $\begin{array}{c}\text { Negative } \\
\text { voltage peak } \\
(\mathrm{kV})\end{array}$ & $\begin{array}{c}\text { Peak } \\
\mathrm{dV} / \mathrm{dt} \\
(\mathrm{MV} / \mathrm{ns})\end{array}$ & $\begin{array}{c}\text { Voltage } \\
\text { signal shown } \\
\text { in Fig. 13 }\end{array}$ \\
\hline 0.8 & 1.2 & 108 & -264 & 1.5 & $\mathrm{a}$ \\
0.8 & 1.5 & 139 & -391 & 2.1 & $\mathrm{~b}$ \\
1.0 & 1.3 & 143 & -332 & 1.7 & $\mathrm{c}$ \\
1.3 & 1.3 & 152 & -313 & 1.8 & $\mathrm{~d}$ \\
1.9 & 1.4 & 165 & -303 & 2.4 & - \\
2.0 & 1.3 & 157 & -340 & 2.1 & $\mathrm{e}$ \\
2.0 & 1.5 & 185 & -312 & 2.0 & $\mathrm{f}$ \\
2.0 & 1.65 & 205 & -353 & 2.7 & $\mathrm{~g}$ \\
2.0 & 1.75 & 229 & -394 & 2.2 & $\mathrm{~h}$ \\
2.1 & 1.65 & 240 & -387 & 2.8 & - \\
2.2 & 1.4 & 176 & -306 & 2.9 & - \\
2.2 & 1.6 & 220 & -339 & 2.7 & - \\
2.2 & 1.65 & 273 & -382 & 2.3 & - \\
2.2 & 1.75 & 232 & -353 & 2.3 & \\
\hline \hline
\end{tabular}
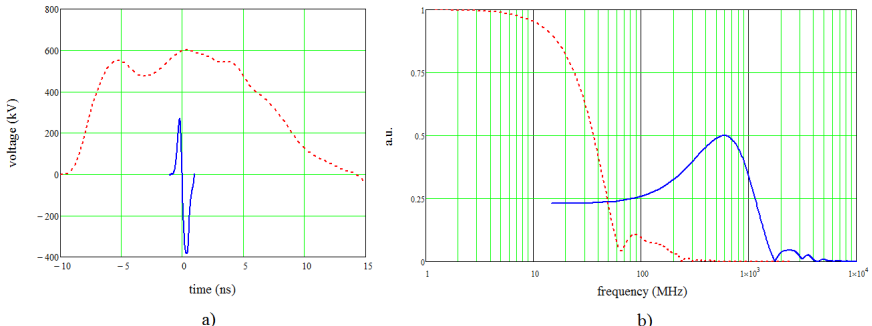

[2] P. Delmote, F. Bieth, S. Pinguet and J. Michel, "Performances of a compact, high-power, wideband and ultra-wideband electromagnetic source," in Proc. UK Pulsed Power Symp., Loughborough, U.K., 2014.

[3] Y. A. Andreev et al., "High-power ultrawideband radiation source," Laser Particle Beams, vol. 21, pp. 211-217, Apr. 2003.

[4] A. M. Efremov, V. I. Koshelev, B. M. Koval'chuk, V. V. Plisko, and K. N. Sukhushin, "Generation and radiation of high-power ultrawideband nanosecond pulses," J. Commun. Technol. Electron., vol. 52, no. 7, pp. 756-764, 2007.

[5] Y. A. Andreev, A. M. Efremov, V. I. Koshelev, B. M. Koval'chuk, V. V. Plisko, and K. N. Sukhushin, "Generation and emission of high-power ultrabroadband picosecond pulses," J. Commun. Technol. Electron., vol. 56, no. 12, pp. 1429-1439, 2011.

Fig. 15. Comparison between the previously demonstrated [1] 600-kV monopolar Blumlein PFL output (dotted red line) and the 650-kV peak-topeak time-compressed and modulated signal generated by the bipolar former (continuous blue line) in (a) time domain and (b) frequency domain.

output signals clearly indicating the resulting improvement obtained in increasing the first positive voltage peak.

Fig. 14 shows the result that best matches the design prediction of Fig. 10, obtained with a gap combination of $2.2 \mathrm{~mm}$ for the connecting switch and $1.65 \mathrm{~mm}$ for the crowbar. The resulting bipolar signal has a first rise time of $\sim 300 \mathrm{ps,} \mathrm{with}$ a peak-to-peak value of $650 \mathrm{kV}$ and a time interval between the two peaks of $\sim 550$ ps. The peak time rate-of-change of the voltage signal is in excess of $2 \mathrm{MV} / \mathrm{ns}$.

\section{CONCLUSION}

The monopolar output of an existing 10-GW-Tesla-driven Blumlein PFL pulsed power generator has been successfully time compressed and modulated using a bipolar former. The resulting sinusoidal-like shape of the bipolar output voltage impulse (Fig. 15) is close to expectations (Fig. 1) and has a peak-to-peak voltage of $650 \mathrm{kV}$ and a high-frequency limit of the bandwidth well in excess of $1 \mathrm{GHz}$ (at $1 \mathrm{GHz}$, the amplitude is $-3.3 \mathrm{~dB}$ from the $550-\mathrm{MHz}$ peak). The generator is now fully prepared for connection to an antenna to begin the study of PEF applications in the medical domain.

\section{REFERENCES}

[1] B. M. Novac, M. Wang, I. R. Smith, and P. Senior, "A 10 GW Tesladriven Blumlein pulsed power generator," IEEE Trans. Plasma Sci., vol. 42, no. 10, pp. 2876-2885, Oct. 2014.

[6] ANSYS, accessed on Nov. 2015. [Online]. Available: http://www.ansys. $\mathrm{com} /$

[7] ORCAD PSpice, accessed on Nov. 2015. [Online]. Available: http:// www.orcad.com/products/orcad-pspice-designer/overview

[8] CST, accessed on Nov. 2015. [Online]. Available: https://www.cst. com/Products

[9] L. Pécastaing, T. Reess, P. Espel, J. Paillol, A. Gibert, and P. Domens, "Investigation of breakdown characteristics of $\mathrm{N}_{2}, \mathrm{SF}_{6}$ and $\mathrm{SF}_{6}-\mathrm{N}_{2}$ mixtures under pressure," in Proc. 11th Int. Symp. High Voltage Eng. (ISH), vol. 3. London, U.K., 1999, pp. 224-227.

[10] G. Bouttemant, L. Pecastaing, J. Paillol, and T. Reess, "High speed pressurised gas breakdown in a high voltage ultrawideband pulse generator," in Proc. 15th Int. Conf. Gas Discharges Appl., vol. 1. Toulouse, France, 2004, pp. 427-430.

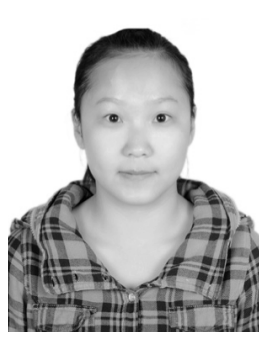

Meng Wang (S'13) was born in China. She received the B.Sc. degree in electronics science and technology from the Huazhong University of Science and Technology, Wuhan, China, in 2011, and the M.Sc. degree in power systems engineering from University College London, London, U.K., in 2012. She is currently pursuing the Ph.D. degree with the Plasma and Pulsed Power Group, Loughborough University, Loughborough, U.K.

Her Ph.D. project is focused on the development of a $10 \mathrm{GW}$ pulsed power generator and the techniques required to modulate its output. Her current research interests include compact and repetitive pulsed power, ultrahigh speed sensors and modeling, and analysis of 3-D electromagnetic systems. 


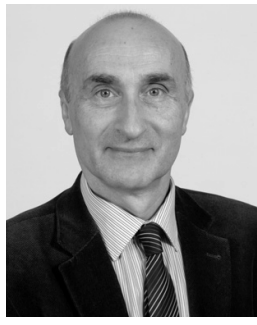

Bucur M. Novac (M'06-SM'08) received the M.Sc. and Ph.D. degrees from the University of Bucharest, Bucharest, Romania, in 1977 and 1989, respectively.

He joined the Loughborough University, Loughborough, U.K., in 1998, where he is currently a Professor of Pulsed Power. He has co-authored two books on explosive pulsed power and has authored over 200 refereed papers and conference contributions. His current research interests include compact and repetitive high-power systems, explosively and electromagnetically driven magnetic flux compression generators and their applications, electromagnetic launchers, ultrafast magneto and electro-optic sensors, and 2-D modeling of pulsed-power systems.

Dr. Novac is a Voting Member of the Pulsed Power Science and Technology Committee in the IEEE Nuclear and Plasma Science Society. He is also a member of the International Steering Committees for the MEGAGAUSS Conferences and the Euro-Asian Pulsed Power Conferences. He is also member of the Organizing Committee of the IEEE International Power Modulator and High Voltage Conference and Co-Chairman of the U.K. Pulsed Power Symposium. He is a Chartered Engineer and a fellow of The Institution of Engineering and Technology, U.K.

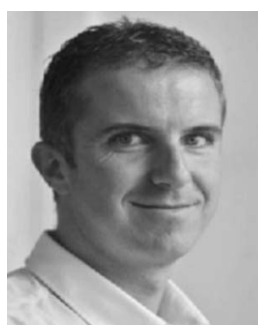

Laurent Pécastaing was born in Bayonne, France, in 1974. He received the Ph.D. degree from the Université de Pau et des Pays de l'Adour, Pau, France, in 2001.

$\mathrm{He}$ is currently a Lecturer with the Laboratoire SIAME, Université de Pau et des Pays de l'Adour. His current research interests include high-power microwave sources, compact pulsed power devices, including pulse-forming lines or Marx generators, and ultrafast transient probes.

Dr. Pécastaing received the Research Directorship Habilitation in electrical engineering from the Université de Pau et des Pays de l'Adour, Pau, France, in 2010.

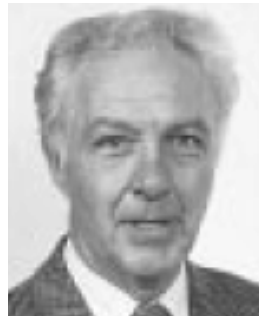

Ivor R. Smith (M'05-SM'11) received the B.Sc., Ph.D., and D.Sc. degrees from the University of Bristol, Bristol, U.K.

He completed the Indentured Student Apprenticeship with General Electric Company Works, Witton, U.K. He became a Lecturer with the University of Birmingham, Birmingham, U.K., subsequently being promoted to Senior Lecturer and Reader. He then moved to Loughborough University, Loughborough, U.K., to become a Professor of Electrical Power Engineering, and served as the Head of Department, the Dean of Engineering and a Pro-Vice Chancellor. For more than 25 years, he has been active in research in many aspects of the production, conditioning and utilization of large pulses of electrical energy.

Dr. Smith is a Chartered Engineer and a fellow of the Institution of Engineering and Technology and the Royal Academy of Engineering. 


\title{
Bipolar Modulation of the Output of a 10-GW Pulsed Power Generator
}

\author{
Meng Wang, Student Member, IEEE, Bucur M. Novac, Senior Member, IEEE, Laurent Pécastaing, \\ and Ivor R. Smith, Senior Member, IEEE
}

\begin{abstract}
A bipolar Blumlein former has been designed and successfully implemented as an extension to an existing 10-GW-Tesla-driven Blumlein pulsed power generator. The new system is capable of generating a voltage impulse with a peak-topeak value reaching $650 \mathrm{kV}$ and having a high-frequency limit of the bandwidth well in excess of $1 \mathrm{GHz}$. Constructional details are provided, together with experimental results and analysis using the 3-D software modeling of the bipolar former that provides the results in good agreement with experimental data.
\end{abstract}

Index Terms-Pulse compression circuits, pulse modulation, pulsed power systems, transient propagation.

\section{INTRODUCTION}

A BROAD range of modern pulsed power applications, including plasma physics, lasers, particle accelerators, aeronautics, outer space science, food industry pulsed-electricfield (PEF) sterilization, bioelectric studies, medical cancer treatment, and the defense industry, require the generation of very fast high-voltage (HV) pulses. The development of a compact Tesla-transformer Blumlein pulse forming line (PFL) pulsed power generator capable of producing a monopolar $0.6 \mathrm{MV}$ voltage impulse with a rise time close to $2 \mathrm{~ns}$ and providing a peak electrical power of $10 \mathrm{GW}$ when connected to a $30 \Omega$ load was reported previously [1]. The first intended application is to use the generator for noninvasive medical cancer treatment, by attaching to its output an antenna to generate intense PEFs. However, it is straightforward to show that a monopolar voltage impulse is not well suited to feeding an antenna and that a bipolar signal will have the following advantages [2].

1) Better suited frequency spectrum, i.e., the low-frequency section of the monopolar pulse with frequencies less than $100 \mathrm{MHz}$, which cannot be radiated by a compact antenna, is greatly reduced in the bipolar pulse spectrum (see Fig. 1).

Manuscript received January 15, 2016; revised April 5, 2016; accepted May 4, 2016.

M. Wang, B. M. Novac, and I. R. Smith are with the Wolfson School of Mechanical, Electrical and Manufacturing Engineering, Loughborough University, Loughborough LE11 3TU, U.K. (e-mail: m.wang4@lboro.ac.uk; b.m.novac@lboro.ac.uk; i.r.smith@lboro.ac.uk).

L. Pécastaing is with the Laboratoire des Sciences de l'Ingénieur Appliquées à la Mécanique et au Génie Electrique, Equipe Génie Electrique, Université de Pau et des Pays de l'Adour, Pau 64053, France (e-mail: laurent.pecastaing@univ-pau.fr).

Color versions of one or more of the figures in this paper are available online at http://ieeexplore.iee.org.

Digital Object Identifier 10.1109/TPS.2016.2569461

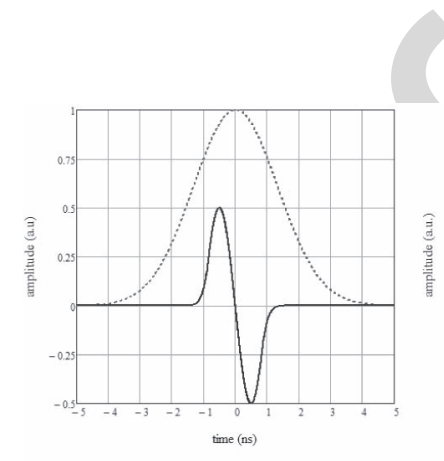

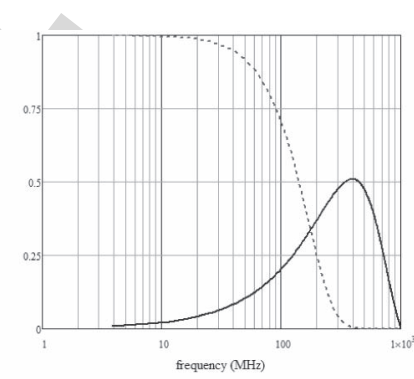

b)
Fig. 1. Comparison between a monopolar signal from a hypothetical generator (dotted red line) and its corresponding bipolar signal obtained from a bipolar former attached to the same generator (continuous blue line) in (a) time domain and (b) frequency domain.

2) Reduced risks of insulation breakdown by flashover include the following.

a) The low-frequency components of a monopolar pulse do not match the antenna characteristics and are reflected back to the generator. This unwanted phenomenon is absent in the case of a bipolar pulse.

b) The peak voltage of the bipolar pulses is only one half that of the peak voltage of the initial monopolar pulse, but, very importantly, the same peak-to-peak amplitude is maintained.

3) The bipolar signal lacks any dc spectral component, thus improving the operator safety, i.e., after a shot there is no risk of a residual charge on the arms of a not yet short-circuited antenna.

4) The technique used to generate a bipolar pulse, using a monopolar pulse as a driver, also usually performs time compression of the driving signal, thereby increasing the upper limit of its frequency spectrum (Fig. 1).

Pioneering work on bipolar formers to modulate the power output from powerful generators has been presented in [3]-[5]. The reported peak bipolar voltage output was $\pm 120 \mathrm{kV}$, with a duration of $1 \mathrm{~ns}$, for the use with a combined frequency transmitting antenna [3], $\pm 200 \mathrm{kV}$ for the use with an antenna array [4] and finally $\pm 350 \mathrm{kV}$, with a duration of $200 \mathrm{ps,}$ also for the use with an antenna array [5]. The application of these spectacular technological achievements is in the domain of high-resolution radars, electromagnetic compatibility, and other defense-related areas, which require for the systems to be capable of continuous operation at a high repetition rate 

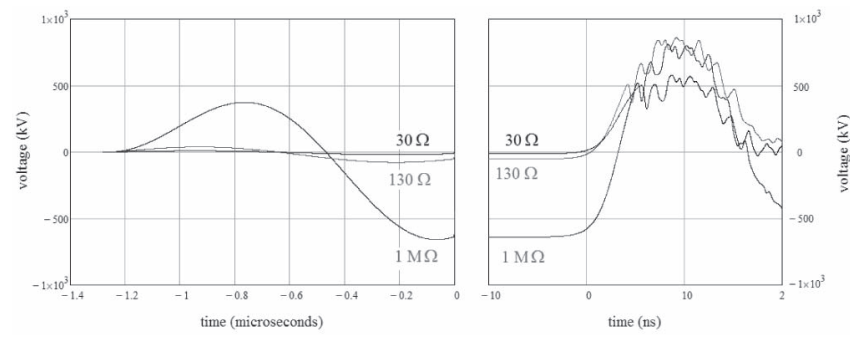

Fig. 2. Results from the PSPICE simulation of the Blumlein-PFL output voltage (left: during unit charging and right: during discharging) for three different values of a parallel-attached resistor: $30 \Omega, 130 \Omega$, and $1 \mathrm{M} \Omega$. Calculations performed with the bipolar former operated only with its seriesconnecting switch, i.e., without a crowbar. The time origin corresponds to closing of the switch that triggers the Blumlein-PFL discharge.

and for hours. This paper details the development of a bipolar former attached to the 10-GW-Tesla-Blumlein generator, with the aim of applying the output voltage impulses to an antenna for medical and biological applications, and for which neither a high repetition rate nor a long duration continuous operation is really required.

After presenting the preliminary work devoted to the changes required to the Blumlein PFL output to allow connection of a bipolar former, the design of the enhanced system is detailed, guided by Maxwell SV [6], PSPICE [7], and CST [8] software modeling. The results obtained during the development program are also presented, before concluding remarks that include a brief comment on the future step toward the development of a powerful PEF generator for medical applications.

\section{AdAPting the Blumlein PFL OUtPUt FOR OPERATION WITH A BIPOLAR FORMER}

The existing 10-GW-Tesla-Blumlein PFL generator has so far been operated with a series-connected $30 \Omega$ resistive load [1]. As PSPICE simulation results show (Fig. 2), simply removing this resistor (equivalent to placing a $1 \mathrm{M} \Omega$ resistor in parallel, as shown in Fig. 2) and attaching the bipolar former to the Blumlein PFL output, or placing the resistor in parallel across the output electrodes $(30 \Omega$ in parallel; see Fig. 2) before attaching the bipolar former, are both unacceptable. In the first situation, the generated voltage has a very large and undesirable negative prepulse that may affect the proper functioning of the bipolar switches, and in the second, the positive amplitude signal is too low to be useful. After a few calculations and preliminary trials, an acceptable compromise solution was found in the form of a $130 \Omega$ resistor parallel-coupled with the Blumlein PFL output. Constructionally, this comprises ten identical aqueous $1.3 \mathrm{k} \Omega$ resistors $\left(\mathrm{CuSO}_{4}\right.$-doped demineralized water) placed in the radialsymmetrical configuration in Fig. 3. To minimize the possibility of electrical flashover, the liquid of each resistor (a liquid length of $100 \mathrm{~mm}$ and a diameter of $15 \mathrm{~mm}$ ) is contained within a Teflon cylinder, with both the inside and outside walls having a ribbed geometry. The resistors are operated under oil and calculations that predict that they will need to withstand a very high-output voltage impulse that may attain a value in

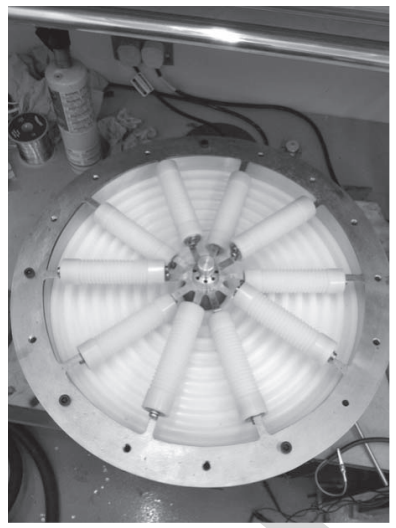

Fig. 3. $130 \Omega$ resistor. When connected to the output of the Blumlein PFL generator, the remaining empty space is filled with transformer oil.

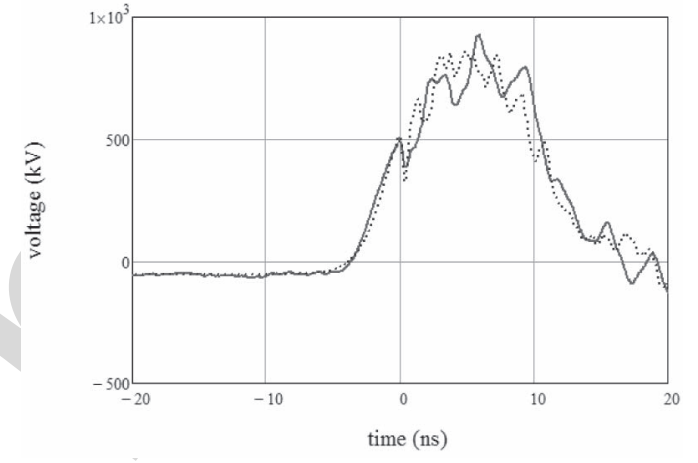

Fig. 4. Blumlein-PFL output voltage with a parallel-connected $130 \Omega$ resistor and a bipolar former operated without a crowbar. Continuous red line: experimental data. Blue dotted line: corresponding PSPICE simulation. The time origin is from the action of the $500-\mathrm{kV}$ bipolar former first closing switch, connecting the unit to the Blumlein PFL.

excess of 0.6 MV, larger than the designed peak voltage inside the Blumlein PFL. A series of experiments was, therefore, performed to test the resistors and the Blumlein PFL under HV loading, by operating the bipolar former (described later) without its second crowbar switch. The results obtained clearly demonstrate that the resistors are capable, together with the central electrode of the Blumlein PFL, of maintaining their electrical integrity up to and even above 0.9 MV (see Fig. 4), a performance well in excess of the design expectations.

\section{Design, Manufacture, And Modeling THE BIPOLAR FORMER}

\section{A. Design and Manufacture}

Fig. 5 shows that the bipolar former has a design similar to that of a conventional Blumlein PFL with two transmission lines each of $25 \Omega$ and a coaxial output of $50 \Omega$, but with two closing switches installed at its input: one in series for connection to the power source (usually not installed in a conventional Blumlein PFL) and the other in parallel (part of a conventional Blumlein PFL) for discharge of the unit. The action of the bipolar former is dictated by the dynamics of the two switches and was presented elsewhere [3], with a much simpler albeit incomplete description being provided in the following. 


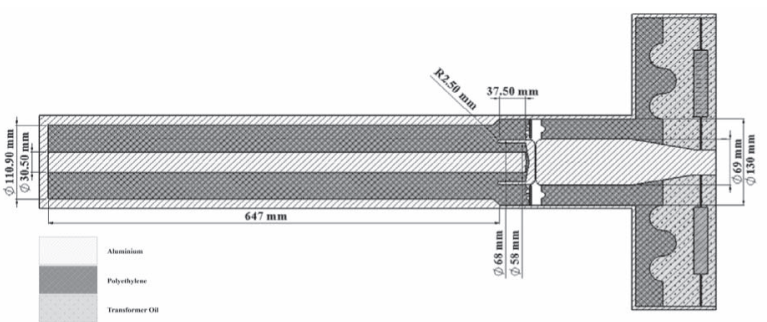

a)

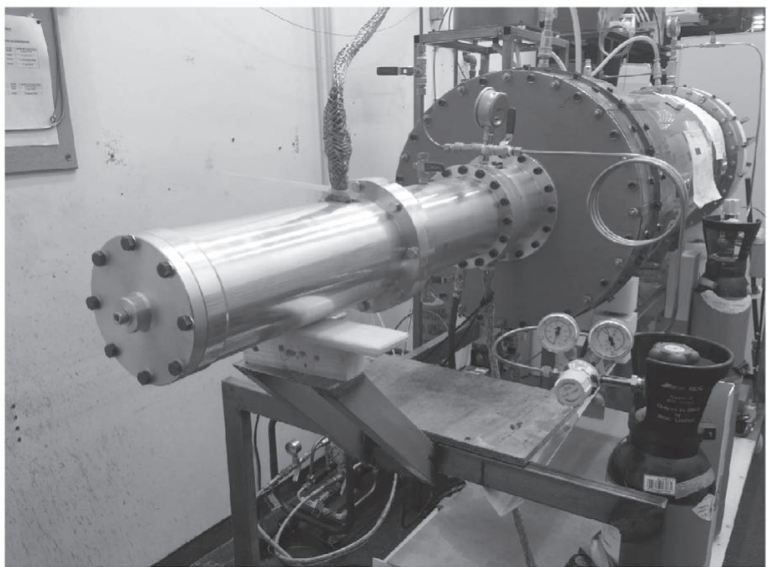

b)

Fig. 5. Bipolar former. (a) Schematic. (b) Assembled unit connected to the Tesla-Blumlein PFL output.

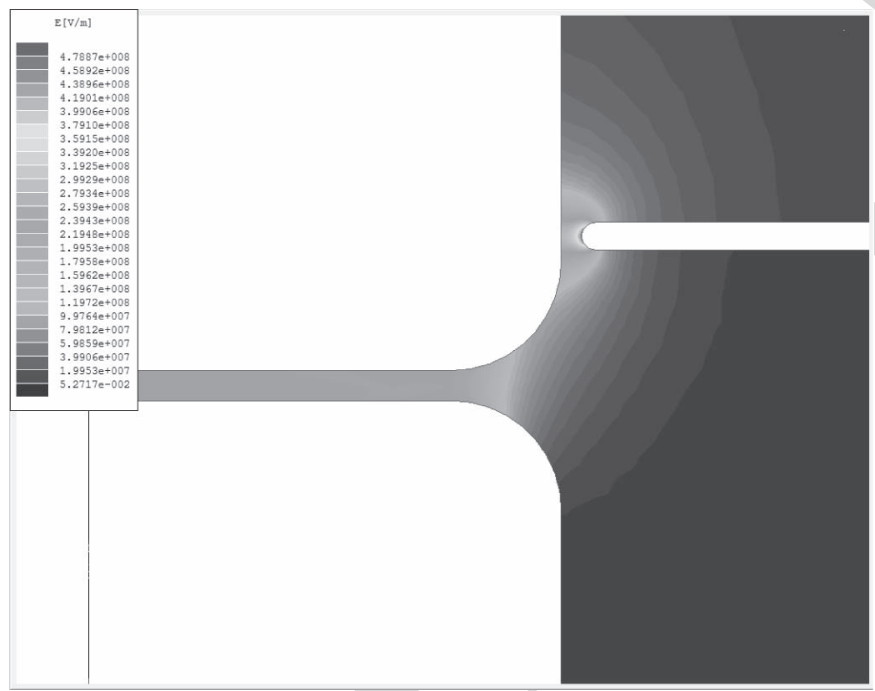

Fig. 6. Electric field distribution produced by the two switches mounted at the bipolar former input, with $0.5 \mathrm{MV}$ applied on the (lower) electrode corresponding to the HV output of the Blumlein PFL.

The positive driving monopolar impulse is allowed to rise to a very HV before the series-connected switch closes, attaching the bipolar unit to the driving generator. The electromagnetic energy transferred from the driving source is capable of very rapidly pulse charging the bipolar former, thereby performing pulse compression of the rise time of the driving monopolar pulse. During charging, a fraction of the fast positive voltage impulse is directly transferred to the load, with the bipolar

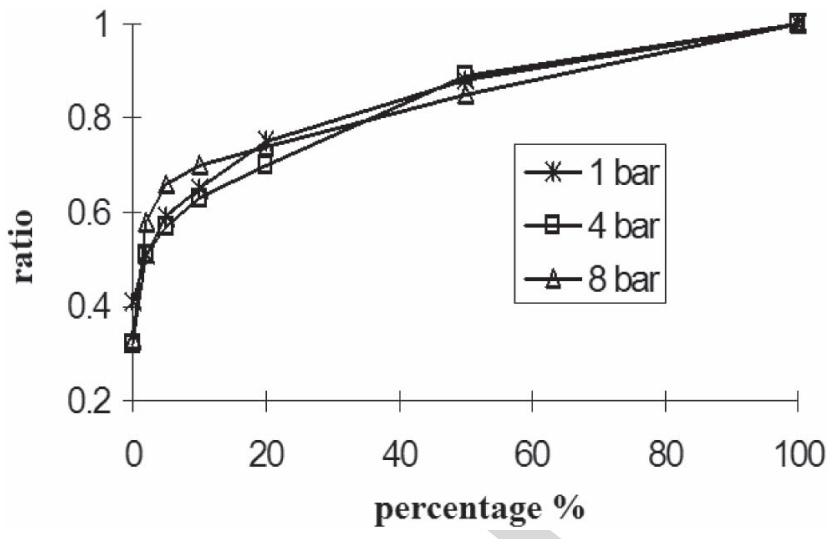

Fig. 7. Influence of percentage $\mathrm{SF}_{6}$ on the ratio of the electric field breakdown for $\mathrm{SF}_{6}-\mathrm{N}_{2}$ mixture to that of pure $\mathrm{SF}_{6}$ [9].

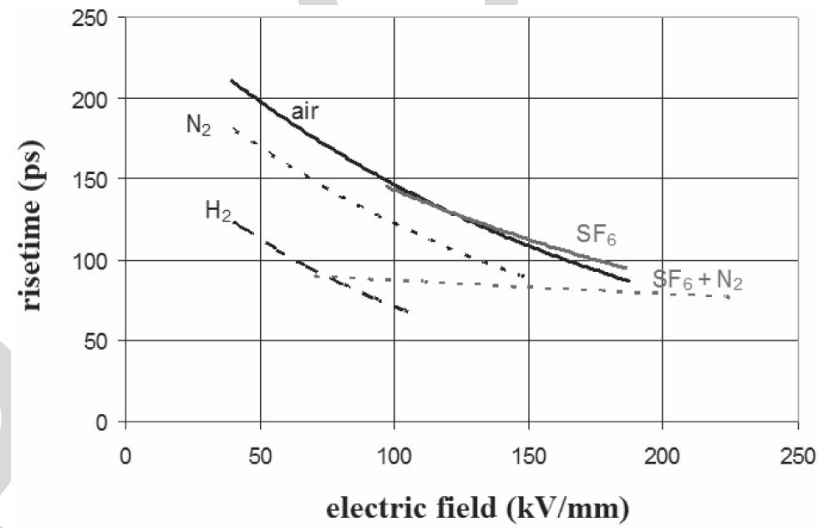

Fig. 8. Experimentally determined rise time of the voltage impulse as a function of the applied electric field for a closing switch using: $\mathrm{H}_{2}$, air, $\mathrm{N}_{2}$, pure $\mathrm{SF}_{6}$, and $\mathrm{SF}_{6}-\mathrm{N}_{2}(5 \%-95 \%)$ mixture [10].

former electrodes playing the role of a capacitive divider. The charging period ends with closure of the second crowbar switch triggering the discharge of the bipolar unit. As usual, discharge of the Blumlein PFL generates a voltage impulse with a polarity opposite to that of the charging polarity, i.e., the voltage generated by the bipolar former discharge in the load is negative. To ensure that the two opposite polarity voltage peaks delivered to the load are close, the gap and the geometry of both switches need to be precisely adjusted during a rather tedious process.

Manufacture of the bipolar former is straightforward, with the metallic electrodes made for convenience from aluminum and the insulators from ultrahigh molecular weight polyethylene of relative permittivity 2.4. During assembly, a thin layer of oil was introduced at each aluminum-polyethylene interface to eliminate any unwanted air. All experiments reported were performed with the $50-\Omega$ coaxial line output short circuited.

\section{B. Closing Switches}

As already mentioned, a pair of closing switches is installed at the bipolar former input. An electrostatic solver [6] was used to calculate both the electric field generated with $500 \mathrm{kV}$ applied to the driver HV electrode (Fig. 6) and also to obtain 


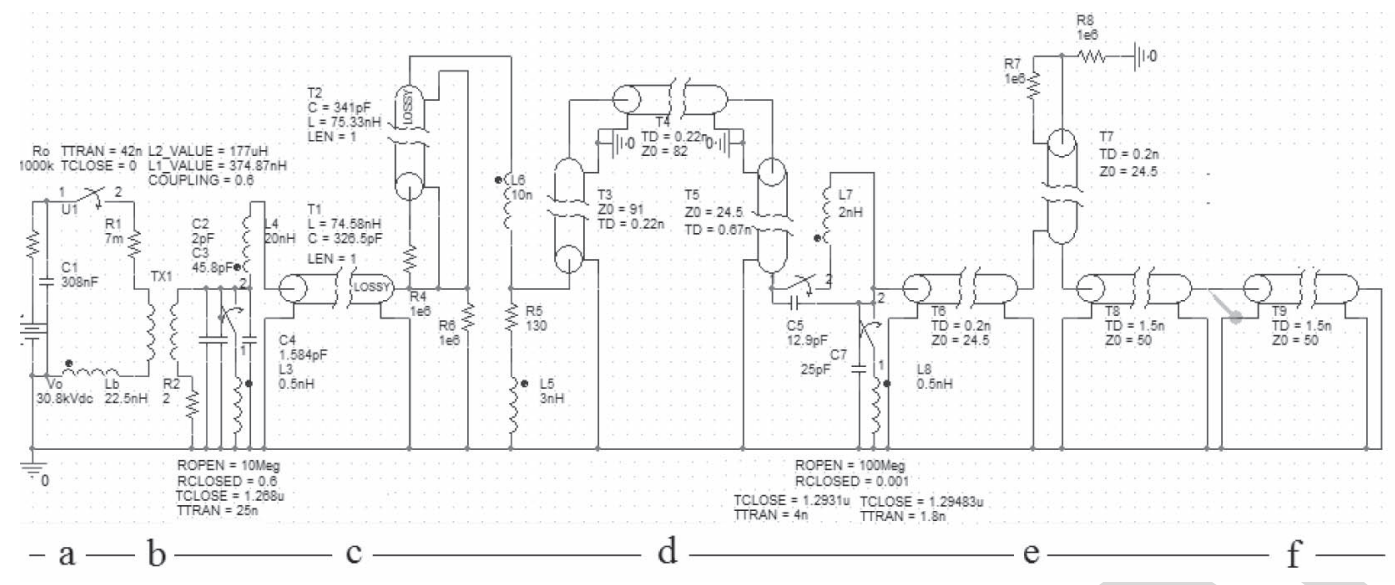

Fig. 9. PSPICE model of the entire pulsed power system. (a) HV charger. (b) Tesla transformer. (c) Blumlein PFL with a closing switch at its input and a $130 \Omega$ resistor parallel-connected at its output. (d) Three very short transmission lines. (e) Bipolar former with two switches mounted at its input. (f) Short-circuited $50-\Omega$ line output.

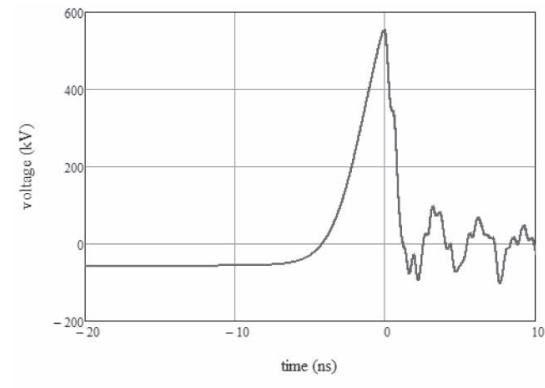

a)

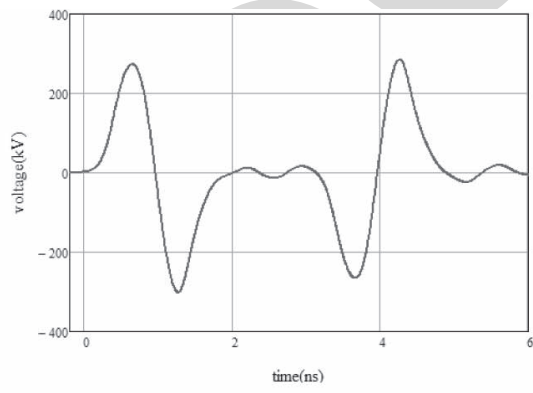

b)

Fig. 10. Main results from PSPICE modeling. (a) Blumlein output voltage impulse. (b) Bipolar voltage generated in the $50-\Omega$ output transmission line, followed by its reversed polarity mirror image produced by reflection at the short-circuited end. In both the cases, the time origin is from closure of the switch connecting the bipolar former to the Blumlein PFL.

the (prebreakdown) capacitances of the two switches, for the use in PSPICE modeling. Both the switches operate in pressurized gas at very $\mathrm{HV}$, and for both, it is desirable to provide the shortest rise time possible. In such cases, the best gas to be used is $\mathrm{H}_{2}$ (due to its low mass density) or, when this presents a risk, the alternative is $\mathrm{N}_{2}$. Both require very high pressures, but, unfortunately, in the present system, the maximum operable overpressure is only $20 \mathrm{bar}$, insufficient for the switches to operate at very $\mathrm{HV}$. In order to withstand $\mathrm{HV}$ levels at lower pressure, $\mathrm{SF}_{6}$ can replace $\mathrm{H}_{2}$ or $\mathrm{N}_{2}$, but, due to its heavier molecular mass, the resulting rise time will become unacceptable long. Previous experience has demonstrated that $\mathrm{SF}_{6}-\mathrm{N}_{2}$ mixtures provide the simplest substitute for pure $\mathrm{SF}_{6}$, with even a small $\mathrm{SF}_{6}$ content resulting in a substantial increase in the breakdown electric field of pure $\mathrm{N}_{2}$. For example, it was experimentally demonstrated [9] that only $10 \%$ of $\mathrm{SF}_{6}$ is required to increase the critical reduced field of pure $\mathrm{N}_{2}$ to $\sim 70 \%$ of that of pure $\mathrm{SF}_{6}$ (Fig. 7). A somehow unexpected benefit, also demonstrated experimentally [10], is that the rise time of a switch operated with certain $\mathrm{SF}_{6}-\mathrm{N}_{2}$ mixtures can be lower than when pure $\mathrm{N}_{2}$ gas is used (Fig. 8). Based on these results, it was decided to operate the bipolar switches at 20 bar in a $10 \%-90 \% \mathrm{SF}_{6}-\mathrm{N}_{2}$ mixture.

\section{Diagnostics}

Three V-dot probes were installed inside the full generator assembly. The first of these, mounted in the outer wall of the Blumlein-PFL, was fully described and its sensitivity $k_{1}$ provided elsewhere [1]. The second and third probes, having sensitivities $k_{2} \approx 0.3 \mathrm{ps}$ and $k_{3} \approx 0.2 \mathrm{ps}$, are made from 18-GHz female-female N-type adaptors and placed, respectively, after the $130 \Omega$ resistor at the Blumlein-PFL transmission line output and in the wall of the bipolar former $50-\Omega$ output transmission line. A detailed study of V-dot probes made from off-the-shelf components is in preparation. These two probes are connected, using double shielded $18-\mathrm{GHz}$ coaxial cables and attenuators, to an $18-\mathrm{GHz}, 60-\mathrm{GS} / \mathrm{s}$ LeCroy real-time digital oscilloscope, with the output of the second probe taken to a 6-GHz-bandwidth input and that of the third probe to an 18-GHz input. The oscilloscope is housed in a Faraday box and powered by a UPS unit.

\section{Numerical Modeling}

Fig. 9 shows the PSPICE model for the entire system (Tesla-Blumlein PFL-bipolar former), and Fig. 10 shows the predicted voltage signal delivered by the bipolar former to the 


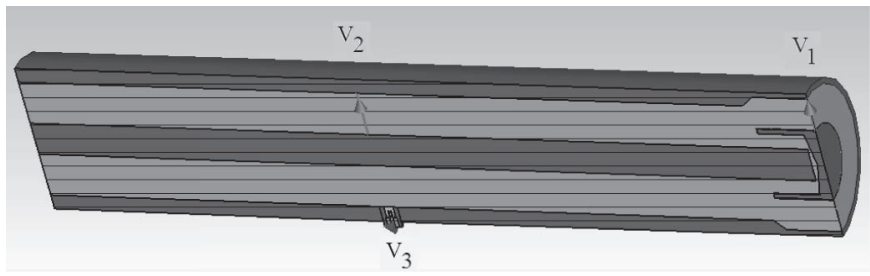

Fig. 11. CST model of the bipolar former. Three CST voltage monitors used in the numerical study are placed as follows: $V 1$ at the unit input (right hand side), $V 2$ across the $50-\Omega$ transmission line at a position corresponding to the (real) V-dot probe, and $V 3$ at the probe output.
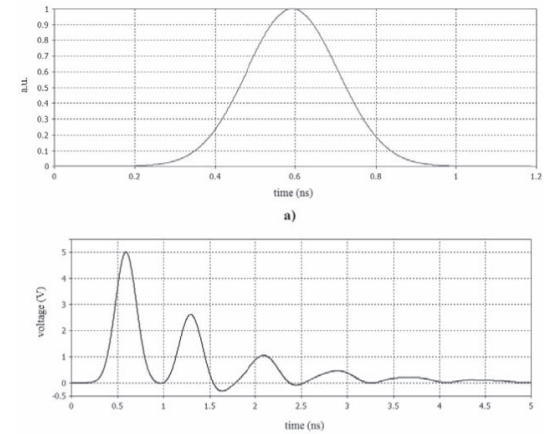

b)
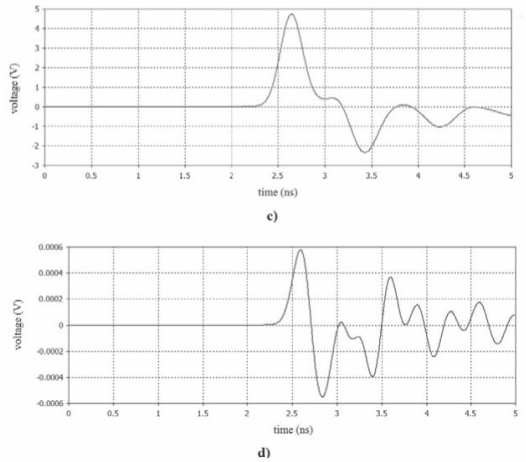

Fig. 12. Main results from CST study of the bipolar former and its V-dot probe. (a) 3-GHz excitation Gaussian signal applied at the input port. Output signals from the three voltage monitors of Fig. 11 are from (b) $V 1$, (c) $V 2$, and (d) $V 3$.

$50-\Omega$ output transmission line when the driver Blumlein-PFL generator operates close to its peak performance [1].

Fig. 11 shows the CST model for the bipolar former, including the V-dot probe inside the wall of the output transmission line. Fig. 12 shows the results with a Gaussian excitation impulse applied at the bipolar former CST input port [Fig. 12(a)] and using three voltage monitors in the software to indicate the voltage signal at various positions inside the unit. After the voltage signal at the input is modulated [Fig. 12(b)], it travels along the transmission line until reaching the position where the V-dot probe is mounted [Fig. 12(c)].

The proper functioning of this differential probe can be investigated by integrating its predicted output signal [Fig. 12(d)] and using the constant $k_{3}$ to compare the result with the voltage signal in Fig. 12(c). Such an analysis, together with a more advanced CST model currently under development and which includes the action of the two closing switches, will be presented elsewhere.

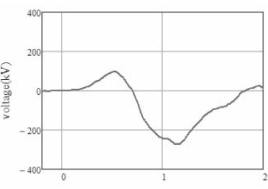

tinction

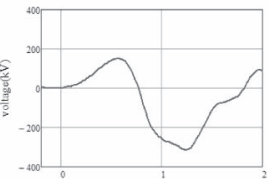

d)

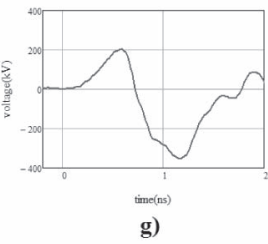

g)

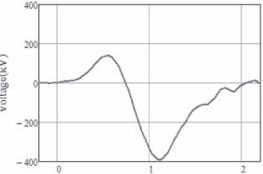

b)

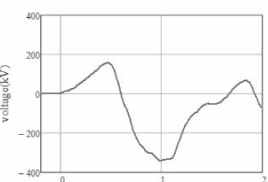

timenta

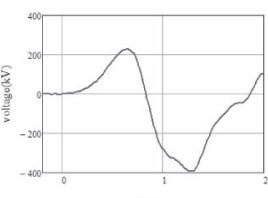

h)

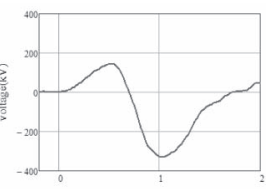

c)

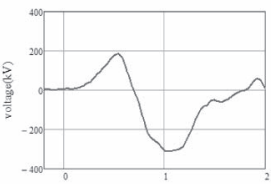

fime(s)

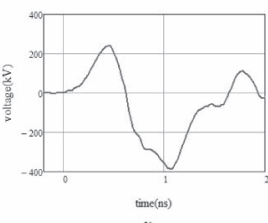

i)
Fig. 13. Load voltage impulses generated by the bipolar former during the process of adjusting the bipolar former switch gaps. Time origin from the connecting bipolar switch closure.
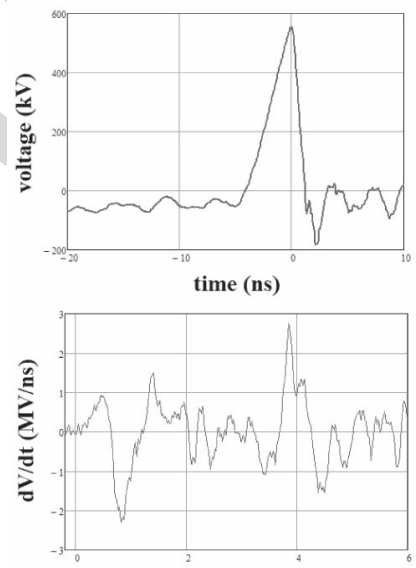

time (ns)

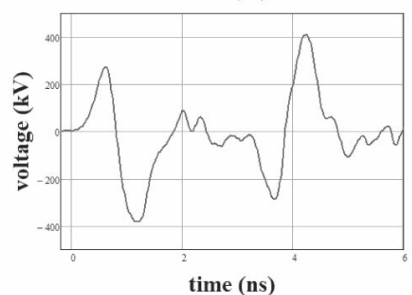

Fig. 14. Typical experimental results from the final pulsed power system. (a) Blumlein PFL output voltage impulse. (b) $d V / d t$ signal recorded by the bipolar output probe. (c) Integrated bipolar voltage developed in the $50-\Omega$ output transmission line, followed by its reversed polarity mirror image produced by reflection at the short-circuited end. In all the cases, the time origin is from the closure of the switch connecting the bipolar former to the Blumlein PFL.

\section{BIPOLAR FORMER EXPERIMENTAL RESUlTS}

Table I presents an overview of the main results obtained from an experimental study to establish the optimum combinations of the gaps of the two switches mounted at the bipolar former input. Correspondingly, Fig. 13 shows a number of 
TABLE I

Results From the Study of the Two Closing Switch Gaps of the Bipolar Former

\begin{tabular}{cccccc}
\hline \hline $\begin{array}{c}\text { Connecting } \\
\text { switch gap } \\
(\mathrm{mm})\end{array}$ & $\begin{array}{c}\text { Crowbar } \\
\text { switch gap } \\
(\mathrm{mm})\end{array}$ & $\begin{array}{c}\text { Positive voltage } \\
\text { peak } \\
(\mathrm{kV})\end{array}$ & $\begin{array}{c}\text { Negative } \\
\text { voltage peak } \\
(\mathrm{kV})\end{array}$ & $\begin{array}{c}\text { Peak } \\
\mathrm{dV} / \mathrm{dt} \\
(\mathrm{MV} / \mathrm{ns})\end{array}$ & $\begin{array}{c}\text { Voltage } \\
\text { signal shown } \\
\text { in Fig. 13 }\end{array}$ \\
\hline 0.8 & 1.2 & 108 & -264 & 1.5 & $\mathrm{a}$ \\
0.8 & 1.5 & 139 & -391 & 2.1 & $\mathrm{~b}$ \\
1.0 & 1.3 & 143 & -332 & 1.7 & $\mathrm{c}$ \\
1.3 & 1.3 & 152 & -313 & 1.8 & $\mathrm{~d}$ \\
1.9 & 1.4 & 165 & -303 & 2.4 & - \\
2.0 & 1.3 & 157 & -340 & 2.1 & $\mathrm{e}$ \\
2.0 & 1.5 & 185 & -312 & 2.0 & $\mathrm{f}$ \\
2.0 & 1.65 & 205 & -353 & 2.7 & $\mathrm{~g}$ \\
2.0 & 1.75 & 229 & -394 & 2.2 & $\mathrm{i}$ \\
2.1 & 1.65 & 240 & -387 & 2.8 & - \\
2.2 & 1.4 & 176 & -306 & 2.9 & - \\
2.2 & 1.6 & 220 & -339 & 2.7 & - \\
2.2 & 1.65 & 273 & -382 & 2.3 & - \\
2.2 & 1.75 & 232 & -353 & 2.3 & \\
\hline \hline
\end{tabular}
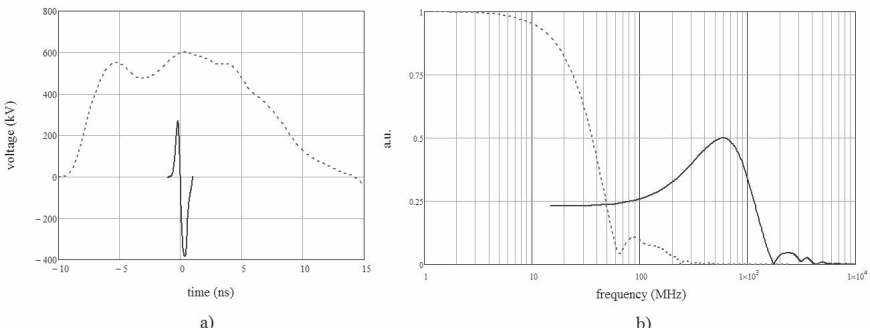

b)

[2] P. Delmote, F. Bieth, S. Pinguet and J. Michel, "Performances of a compact, high-power, wideband and ultra-wideband electromagnetic source," in Proc. UK Pulsed Power Symp., Loughborough, U.K., 2014.

[3] Y. A. Andreev et al., "High-power ultrawideband radiation source," Laser Particle Beams, vol. 21, pp. 211-217, Apr. 2003.

[4] A. M. Efremov, V. I. Koshelev, B. M. Koval'chuk, V. V. Plisko, and K. N. Sukhushin, "Generation and radiation of high-power ultrawideband nanosecond pulses," J. Commun. Technol. Electron., vol. 52, no. 7, pp. 756-764, 2007.

[5] Y. A. Andreev, A. M. Efremov, V. I. Koshelev, B. M. Koval'chuk, V. V. Plisko, and K. N. Sukhushin, "Generation and emission of high-power ultrabroadband picosecond pulses," J. Commun. Technol. Electron., vol. 56, no. 12, pp. 1429-1439, 2011.

Fig. 15. Comparison between the previously demonstrated [1] 600-kV monopolar Blumlein PFL output (dotted red line) and the $650-\mathrm{kV}$ peak-topeak time-compressed and modulated signal generated by the bipolar former (continuous blue line) in (a) time domain and (b) frequency domain.

output signals clearly indicating the resulting improvement obtained in increasing the first positive voltage peak.

Fig. 14 shows the result that best matches the design prediction of Fig. 10, obtained with a gap combination of $2.2 \mathrm{~mm}$ for the connecting switch and $1.65 \mathrm{~mm}$ for the crowbar. The resulting bipolar signal has a first rise time of $\sim 300 \mathrm{ps}$, with a peak-to-peak value of $650 \mathrm{kV}$ and a time interval between the two peaks of $\sim 550 \mathrm{ps}$. The peak time rate-of-change of the voltage signal is in excess of $2 \mathrm{MV} / \mathrm{ns}$.

\section{CONCLUSION}

The monopolar output of an existing 10-GW-Tesla-driven Blumlein PFL pulsed power generator has been successfully time compressed and modulated using a bipolar former. The resulting sinusoidal-like shape of the bipolar output voltage impulse (Fig. 15) is close to expectations (Fig. 1) and has a peak-to-peak voltage of $650 \mathrm{kV}$ and a high-frequency limit of the bandwidth well in excess of $1 \mathrm{GHz}$ (at $1 \mathrm{GHz}$, the amplitude is $-3.3 \mathrm{~dB}$ from the $550-\mathrm{MHz}$ peak). The generator is now fully prepared for connection to an antenna to begin the study of PEF applications in the medical domain.

\section{REFERENCES}

[1] B. M. Novac, M. Wang, I. R. Smith, and P. Senior, "A 10 GW Tesladriven Blumlein pulsed power generator," IEEE Trans. Plasma Sci., vol. 42, no. 10, pp. 2876-2885, Oct. 2014.

[6] ANSYS, accessed on Nov. 2015. [Online]. Available: http://www.ansys. $\mathrm{com} /$

[7] ORCAD PSpice, accessed on Nov. 2015. [Online]. Available: http:// www.orcad.com/products/orcad-pspice-designer/overview

[8] CST, accessed on Nov. 2015. [Online]. Available: https://www.cst. com/Products

[9] L. Pécastaing, T. Reess, P. Espel, J. Paillol, A. Gibert, and P. Domens, "Investigation of breakdown characteristics of $\mathrm{N}_{2}, \mathrm{SF}_{6}$ and $\mathrm{SF}_{6}-\mathrm{N}_{2}$ mixtures under pressure," in Proc. 11th Int. Symp. High Voltage Eng. (ISH), vol. 3. London, U.K., 1999, pp. 224-227.

[10] G. Bouttemant, L. Pecastaing, J. Paillol, and T. Reess, "High speed pressurised gas breakdown in a high voltage ultrawideband pulse generator," in Proc. 15th Int. Conf. Gas Discharges Appl., vol. 1. Toulouse, France, 2004, pp. 427-430.

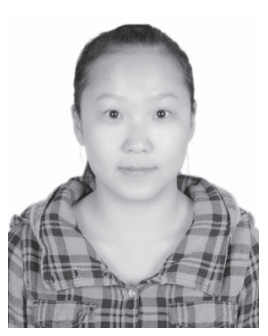

Meng Wang (S'13) was born in China. She received the B.Sc. degree in electronics science and technology from the Huazhong University of Science and Technology, Wuhan, China, in 2011, and the M.Sc. degree in power systems engineering from University College London, London, U.K., in 2012. She is currently pursuing the Ph.D. degree with the Plasma and Pulsed Power Group, Loughborough University, Loughborough, U.K.

Her Ph.D. project is focused on the development of a $10 \mathrm{GW}$ pulsed power generator and the techniques required to modulate its output. Her current research interests include compact and repetitive pulsed power, ultrahigh speed sensors and modeling, and analysis of 3-D electromagnetic systems. 


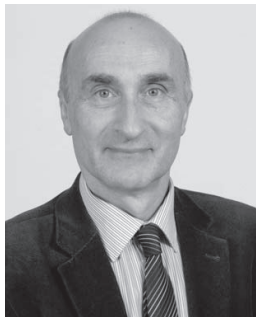

Bucur M. Novac (M'06-SM'08) received the M.Sc. and Ph.D. degrees from the University of Bucharest, Bucharest, Romania, in 1977 and 1989, respectively.

He joined the Loughborough University, Loughborough, U.K., in 1998, where he is currently a Professor of Pulsed Power. He has co-authored two books on explosive pulsed power and has authored over 200 refereed papers and conference contributions. His current research interests include compact and repetitive high-power systems, explosively and electromagnetically driven magnetic flux compression generators and their applications, electromagnetic launchers, ultrafast magneto and electro-optic sensors, and 2-D modeling of pulsed-power systems.

Dr. Novac is a Voting Member of the Pulsed Power Science and Technology Committee in the IEEE Nuclear and Plasma Science Society. He is also a member of the International Steering Committees for the MEGAGAUSS Conferences and the Euro-Asian Pulsed Power Conferences. He is also member of the Organizing Committee of the IEEE International Power Modulator and High Voltage Conference and Co-Chairman of the U.K. Pulsed Power Symposium. He is a Chartered Engineer and a fellow of The Institution of Engineering and Technology, U.K.

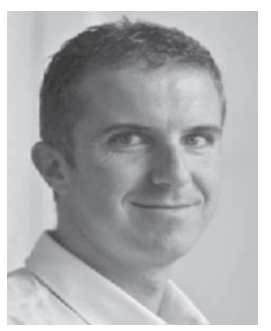

Laurent Pécastaing was born in Bayonne, France, in 1974. He received the Ph.D. degree from the Université de Pau et des Pays de l'Adour, Pau, France, in 2001.

$\mathrm{He}$ is currently a Lecturer with the Laboratoire SIAME, Université de Pau et des Pays de l'Adour. His current research interests include high-power microwave sources, compact pulsed power devices, including pulse-forming lines or Marx generators, and ultrafast transient probes.

Dr. Pécastaing received the Research Directorship Habilitation in electrical engineering from the Université de Pau et des Pays de l'Adour, Pau, France, in 2010.

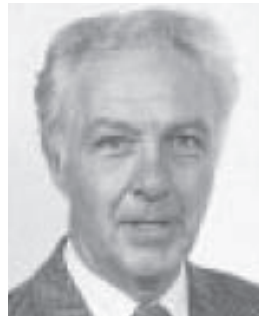

Ivor R. Smith (M'05-SM'11) received the B.Sc., $\mathrm{Ph} . \mathrm{D}$., and D.Sc. degrees from the University of Bristol, Bristol, U.K.

He completed the Indentured Student Apprenticeship with General Electric Company Works, Witton, U.K. He became a Lecturer with the University of Birmingham, Birmingham, U.K., subsequently being promoted to Senior Lecturer and Reader. He then moved to Loughborough University, Loughborough, U.K., to become a Professor of Electrical Power Engineering, and served as the Head of Department, the Dean of Engineering and a Pro-Vice Chancellor. For more than 25 years, he has been active in research in many aspects of the production, conditioning and utilization of large pulses of electrical energy.

Dr. Smith is a Chartered Engineer and a fellow of the Institution of Engineering and Technology and the Royal Academy of Engineering.

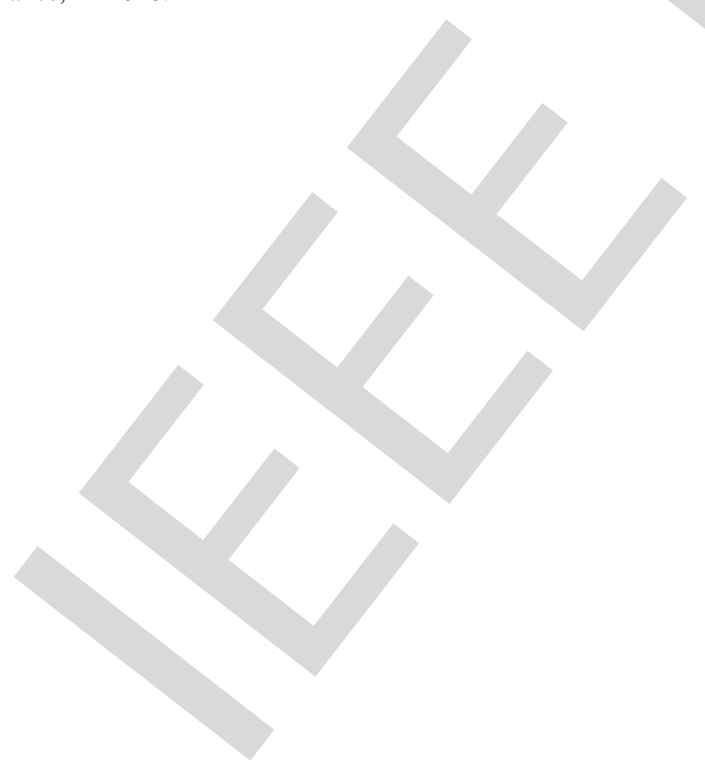

